\title{
Innovative Thinking of Elementary Course Teaching in University
}

\author{
Xuelian Lu \\ Tonghua Normal University, College of Education Science, Jilin Province, Tonghua City, \\ 134002, China \\ luxuelian1982@sina.com
}

\begin{abstract}
As one of the important part of higher education, the elementary course teaching has its unique features and rules from other professional course teachings. Its main teaching content is to teach knowledge and its purpose is to foster students' abilities. Being an elementary, important, scattered and long-term course, the teacher needs to undertake heavy tasks and great duties. According to its features and inner rules, the innovative elementary course teaching should combine its teaching contents with higher education's training objectives, combine promoting teacher qualities with evaluation of teaching quality, combine exploring its teaching characteristics with the study of teaching theories and combine carrying out the modern teaching ideas with training innovative talents.
\end{abstract}

Keywords: Higher Education; Elementary Course Teaching; Innovative teaching; Training Objective; Evaluation of Teaching Quality; Training of Innovative Talents.

\section{院校基础课教学的创新性思考}

\section{陆雪莲 \\ 国家通化师范学院教育科学学院, 吉林通化 中国}

摘 要: 基础课教学作为高等教育中一个重要环节, 有其与专业课教学不同的特点和规律。基 础课教学是以传授知识为主线、以培养能力为根本, 其任务繁重, 责任重大, 具有基础性、 重要性、分散性和长效性等特点。根据基础课教学的特点和内在规律, 基础课创新性教学必 须做到基础课教学内容与院校培养目标相结合、提升教师素质与教学质量评估相结合、探索 基础课教学特点规律与教学理论研究相结合、贯彻现代教学理念与创新型人才培养相结合。

关键词: 高等教育; 基础课教学; 创新性教学; 培养目标; 教师教学质量评估; 创新型人才 培养

\section{1. 前言}

《面向 21 世纪教育振兴行动计划》中指出：实施 “高层次创造性人才工程”，高等学校要跟 踪国际学术发展前沿, 成为知识创新和高层次创新型人才培养的基地, 要重视培养高层次创 新性人才的团结协作和奉献精神 $[1]$ 。人才培养质量始于高校教学质量, 而在高等院校教学改 革深入发展的新形势下, 如何使基础课教学更加有效地服务于人才培养目标, 亟需认真思考 和探讨。

在课题研究中, 从收集到的文献资料来分析, 将高校基础课教学作为一个研究专题并进行系 统分析的文献是比较少的, 且这些研究主要集中于某一科目课程上, 对整个基础课教学的整 体分析与研究几乎为零。而本课题结合地区高校基础课教学的整体情况, 根据基础课的特点 和规律, 创新性的提出高校基础课教学的宏观策略。 


\section{2. 基础课创新教学的策略}

2. 1. 基础课教学内容与院校培养目标相结合

教学内容直接反映院校教学目的和人才培养的目标, 是教育创新的核心。院校培养目标是为 了满足各行各业、各个社会层次的人才需求和不同年龄层次受教育者的学习需求而设置, 是 教育目的在各级各类院校的具体化, 由特定社会领域和特定社会培养目标层次的需要所决定, 随着受教育者所处学校类型、级别而变化。各级各类学校要完成各自的任务, 培养社会需要 的合格人才, 就要制定各自的培养目标。院校的教学内容与培养目标是密切相连的, 基础课 的教学内容取决于院校的培养目标。

一般说来院校的基础课教学包括公共基础课教学和专业基础课教学, 而基础课教学也不能简 单地理解成只为专业课打基础, 基础课教学实际上是人才培养的重要阶段和必要环节, 与专 业教学起着同等甚至更为重要的作用。特别是在当今注重厚基础、宽专业的教学模式下, 基 础课教学显得更加关键和重要, 这些基本观念得到越来越多教育者的认同和支持。加强基础 课教学必须着眼于院校建设与发展大局的需要, 紧盯院校培养目标进行细化分解、分类规范, 增强教学的实效性。要围绕培养素质及技能过硬的人才, 科学创设教学科目, 稳步推进教育 进度, 充分发挥基础课教学 “强基固本” 的作用。基础课教学还要充分利用基础教学资源, 扩展基础教学网络, 建立资源共建共享的长效管理机制, 充分发挥教师在资源建设中的核心 主导作用, 注重教学的实际需求, 契合教师的教学思想和方法; 建设和维护资源共建共享平 台, 为教师开展资源建设和教学研究提供支撑服务、业务指导和技术支持, 为教师的资源开 发提供高质量的技术服务。基础教学网络的具体操作, 需要从队伍建设和运行机制、激励机 制建设、投入机制建设等方面着手，使基础课教学更加贴近院校培养目标 [2]。

2.2. 提升教师素质与教学质量评估相结合

百年大计, 教育为本; 教育大计, 教师为本, 教师是教学的主导。基础课教师必须具备高尚 的思想道德素质, 先进的科学思想, 扎实的专业理论和深厚的教学功底, 富有创新意识和创 新能力, 并能影响学生道德品质的形成。教学实践证明, 基础课教师队伍除了应具有较高的 政治素质以外, 其专业能力和业务素质对教学质量起着决定性作用, 必须作为重中之重扭住 不放, 抓紧抓好。要根据基础课教学的特点, 科学制定课堂教学质量评估标准和具体要求, 包括: 教学理念新, 充分体现素质教育和创新教育; 教学设计科学合理, 具有鲜明的教学风 格和教学特色; 课堂授课富有热情, 具有较强的艺术性和感染力; 思路清晰, 教案规范, 阐 述准确, 重点难点突出; 内容充实, 难度、深度、广度和信息量适宜; 根据教学对象需要, 反应本学科专业前沿知识和最新成果; 理论联系实际, 突出学科专业实践; 教学方法灵活, 教学手段使用恰当; 善于调动学生情绪, 课堂互动性好; 勤奋敬业, 治学严谨, 具有良好的 为师气质 [3]。

针对基础课教师要构建量化直观的教学质量评估体系, 强化教育实施全程的目标管理, 坚持 在教育步骤规范化、教育目标分阶段量化、教育效果评估准确化上下功夫, 使教育始终沿着 程度走, 朝着目标走, 跟着考评走。增强考核规范性, 变概略化的总体性考核为精确化的阶 段性考核, 变随意选定考核内容为严格设置考核内容; 增强考核经常性, 变年终一考定乾坤 为阶段总结性考核, 变被动应考为主动自考; 增强考核实践性, 变重数量为重效果; 增强考 核约束性, 像看考试成绩一样看教书育人能力的提高效果, 要把能力提高的成绩与单位及领 导的评先、使用挂起钩来，真正达到以考促教的目的 [4]。

2. 3. 探索基础课教学特点规律与教学理论研究相结合

基础课教学作为院校教育中一个重要环节, 有其与专业课教学不同的特点和规律。充分认识 基础课教学基本特点, 找准基础课教学内在规律。基础课教学任务繁重, 责任重大, 具有基 础性、重要性、分散性和长效性等特点。其教学的内在规律表现为: 基础课教学质量是基础 课教学的生命线; 以传授知识为主线, 培养能力为根本; 指导学生完成思维的转变, 奠定必 要的文化基础和科学素养, 与专业教学和应用相结合, 创造生机和活力; 以学科为依托, 加 强教学、学术与科学研究, 提高教学水平。 
加强基础课教学理论和教学规律研究, 有效指导教学实践。加强基础课教学研究, 就是根据 专家学者教学理论研究成果中提出的新思想、新理论, 结合基础课教学的特点规律所进行的 探索性研究, 研究内容包括对教学大纲、教学内容、教学方法手段、教学对象、教学评估和 教育者本身等方面的研究。依据教学大纲设计教学目标; 依据教学目标整合教学内容, 要求 突出重点、难点; 依据教学内容制定教学环节或教学过程; 为每个教学环节设计恰当的学习 情境和探讨活动; 对照教学目标反思教学环节及其活动的教学价值。通过对上述内容的研究, 制定科学实用的基础课课程教学设计和课堂教学方案, 精心实施教学计划, 以期达到预期的 教学效果。

建立健全基础课教学理论研究制度和长效机制。为了使基础课教学更好地服务于全校的整体 教学, 有必要建立长期有效的教学理论研究制度, 内容包括更好地跟踪基础学科发展变化动 态, 了解分析国家和高等院校基础教学现状与最新成果; 组织承担基础课教学交流研讨活动 和有关科研项目, 成立基础课教学专家咨询指导委员会, 跟踪指导一线教学, 研究提出对基 础课教学的对策建议, 对基础课教学进行全面指导和科学管理 [5]。

2. 4. 贯彻现代教学理念与创新型人才培养相结合

构建新的教学策略, 优化教学形式。良好的教学形式能吸引学生的注意力, 调动学生学习兴 趣, 最大程度地开发学生的思维能力。这就要求教师在课堂上应灵活采用讲授教学法、情景 教学法、多媒体教学法、案例教学法、课堂讨论教学法、图文教学法等丰富多样的教学形式, 用其丰富的知识、幽默的语言, 培养学员对学习的兴趣, 积极主动地参与课堂活动, 与教师 共同讨论教学内容 [6]。

注重学生个性发展, 激发创新潜能。所谓个性就是指特性, 与人才成长成正比。没有个性发 展, 就很难有创造性。只有个性得到充分发展与发挥, 探索求知的欲望得以调出和满足, 才 可能发现新问题, 做出新成绩, 才能孕育出真正的创造力。因此, 教学中应坚持因材施教, 分层次培养, 让有能力的学生优先发展, 从而最大限度地激发其创新潜能。

重视训练学生的思维能力和自学能力, 培养思维品质。培养学生的思维能力主要包括发散思 维与聚合思维两种形式, 是创造性思维的基本形式。思维由集中而发散, 由发散而集中, 进 而提出新设想、新见解或尝试新的方法去解决问题。通过培养学生的自学能力, 使其广阔的 思维品质、创新能力在学习过程中得到培养。

重视培养学生的表现力, 鼓励他们积极参与教学活动。在传统的课堂教学中, “填鸭式”、

“满堂灌” 传授知识的教学模式严重地制约了学生参与课堂活动的积极性。教师要有计划有 目的地给学生提供动手和表达的条件与机会, 让其发现新问题新方法, 使学生通过讨论、实 验、提问、演讲、作业等多种形式的练习, 掌握知识, 培养能力, 发展、创造个性。

正确处理好师生关系, 营造宽松的学习氛围。“亲其师、信其道”, “创造力量最能发挥的 条件是民主”, 民主和谐的学习环境有利于学生形成创造性思维, 创造发展个性。只有在平 等宽松和谐的氛围中, 学生才能轻松愉快的学习, 才能取得预期的良好学习效果。教师要以 真诚的眼光注视学生, 亲切的语气教育学生, 信任的态度引导学生; 激励学生自主意识, 活 跃学生创造性思维, 激发学生想象力, 以提高学生的综合素质。教师在具有良好的人格品质 和创新精神的同时, 要注意与学生建立民主、宽松、和谐、相互尊重、相互理解的关系, 创 设良好的教学氛围。

\section{3. 结论}

高等院校基础课程是学生学习的基础理论、基本知识和基本技能的课程, 能为学生掌握专业 知识、学习科学技术、发展能力打下坚实的基础, 并能指导学生完成思维的转变。基础课教 学质量是基础课教学的生命线, 充分认识和把握其特点规律, 深入探讨基础课创新性教学策 略, 对加强和改进基础课教学, 有效地提高教学质量具有重要意义。人类的科学进步是靠具 有创新思想和创造才能的人创造的, 我们所从事的教育就是这种创造的 “奠基石” 和 “金钥 
匙” 。高等院校基础课教学必须始终贯彻创新教育的现代教学理念, 注重学生创新能力的培 养和发展。

\section{References}

[1].Information on:http://www.gmw.cn/01gmrb/1999-02/25/GB/17978\%5EGM3-2505.HTM

[2].Ping Li, Shengyi Zhong, Junyan Li, et al. For Reference of French Pattern, Exploring new Teaching Ideas of Engineering Elementary Course [J].The Study of Higher Engineering Education. The 2nd Issue of 2015, P.20-28.

[3].Xuelian Lu. Construction of the Connotation and Standard of Developmental Evaluation of Students[J].Teaching and Administrating.vol.36,no.36,2013,p.71-73.

[4].Xuelian Lu. On the Cultivation of Teaching Capability of the 80's Teachers in Institutions of Higher Education.[J].Theory and Practice of Education.vol.33,no.36,2013,p.51-52.

[5].Qiuqian Song, Aizhen Pan. The Survey and Thinking of Higher School's Public Elementary Course Teaching Effectiveness [J].Teachings in Chinese Universities. The 5th Issue of 2009, P.18-21.

[6].Xuming He. Popular:The Keys of Effective College Teaching[J].Teachings in Chinese Universities. The 8th Issue of 2009, P.18-21. 